Military Technical College

Kobry El-Kobbah,

Cairo, Egypt.

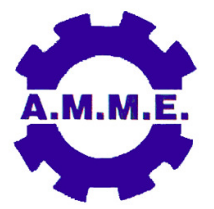

$17^{\text {th }}$ International Conference on Applied Mechanics and Mechanical Engineering.

\title{
INFLUENCE OF SINTERING TEMPERATURE, GLASS AND STARCH POWDER ON COMPRESSION PROPERTIES OF CARBON STEEL FOAM CONTAINING 10\% MILL SCALE
}

\author{
S. N. Ghali ${ }^{\star}$
}

\begin{abstract}
Influence of sintering temperature, addition of glass powder or starch to carbon steel powder on compressive properties of foam steel was investigated. Two groups of foam steels were produced, both groups were including carbon steel powder and mill scale (10\%), the first one was including from 3\%-12\% glass powder while the second group was including starch (3\%-12\%). All powder components were good mixed and then $6 \%$ phosphoric acid was added. The green specimens were sintered at $1100^{\circ} \mathrm{C}$, $1150{ }^{\circ} \mathrm{C}$ and $1200{ }^{\circ} \mathrm{C}$ for $60 \mathrm{~min}$ in carburizing atmosphere. The apparent density of sintered specimens were measured, it was found in the range of $0.60-1.38 \mathrm{gm} / \mathrm{cm}^{3}$. The compressive strengths of sintered specimens contain starch and glass powder were 31-52.7 MPa, 27 - 39.5 MPa respectively. The measured compression strengths were compared with the predicted publishing work. It was found that the measured results were in a good agreement with the predicted ones.
\end{abstract}

\section{KEY WORDS}

Foam steel, low-density steel, powder, sintering, light material, compression and density.

\footnotetext{
* Associate professor, Steel Technology Department, Central Metallurgical Research and Development Institute (CMRDI), Cairo, Egypt.
} 


\section{INTRODUCTION}

Metallic foams are known for their interesting combinations of physical and mechanical properties such as high stiffness in conjunction with very low specific weight or high compression strengths combined with good energy absorption characteristics. Although interest in these materials is increasing, some confusion exists concerning the term "metallic foam," which is often used in a general way to describe materials that are not foams in the strictest sense [1].

Metal foams are a class of materials with extremely low densities and an outstanding combination of mechanical, electrical, thermal, and acoustic properties. They offer a large potential for lightweight structures with high stiffness and high mechanical properties, energy absorption, and thermal management. Their extraordinary property combinations make them interesting for applications where more than one function can be met.

There are different production methods for metallic foams such as foaming of Melts by Gas Injection (Hydro/Alcan) [2-7], foaming of melts with blowing agents (Alporas) [8-9], Solid-Gas Eutectic Solidification (Gasar) [10], foaming of powder compacts (Foaminal/Alulight) [11-17] and foaming of ingots containing blowing agents (Formgrip/Foamcast) [18-19].

The effect of addition glass and starch powder on steel foam properties were investigated by using slip casting process [20]. This article aims at investigation the effect of addition of glass powder and starch to mixture from carbon steel and mill scale powder on compression test and apparent density. In addition to, the influence of sintering temperature will be illustrated. The compression results was compared with the deduced ones of publishing work [21].

\section{EXPERIMENTAL}

Sieve analysis was carried out for iron powder, mill scale, glass powder and starch. The heat experiment was prepared through the following steps; $90 \mathrm{gm}$ iron powder with $10 \mathrm{gm}$ mill scale mixes with $3 \mathrm{gm}, 6 \mathrm{gm}, 9 \mathrm{gm}$ or $12 \mathrm{gm}$ glass powder (first group) or starch powder (second group). $0.5 \mathrm{gm}$ carbon powder was added for each heat. Then $25 \mathrm{ml}$ ortho-phosphoric acid (its concentration 6\%) was added to form green sample. Starch act as a binder and glass powder act as a dispersant. Orthophosphoric acid acts as a foaming agent where it is a source of gas. The sintering process was carried out in muffle furnace in presence of reducing agent (carbon) to prevent oxidation process for the green samples.

The green samples were sintered at $1000^{\circ} \mathrm{C}, 1100^{\circ} \mathrm{C}$ and $1200^{\circ} \mathrm{C}$ for 1 hour. The method of measuring apparent density is Archimedes method, where the foam sample with dimension 65-70 mm diameter with height about $10-13 \mathrm{~mm}$ was weighted in open air and then the sample covered by a thin plastic cover and immersed in water, the displacement of water was measured to determine the actual volume. The density was calculated from mass and volume. Apparent density was calculated. 
The static compression test was carried out for the sintered foam samples. Compression dimensions of measured foam samples was ranging from $65 \mathrm{~mm}$ to 70 $\mathrm{mm}$ diameter and the height was about $10-13 \mathrm{~mm}$. The rate of loading of compression test was $2 \mathrm{~mm} / \mathrm{min}$. The static compression properties was compared with the expected results from currently published model [21].

\section{RESULTS AND DISCUSSIONS}

Chemical composition of iron powder, mill scale are listed in Tables (1 - 2). The sieve analysis of iron powder, mill scale, starch, and glass powder are shown in Figs.( -4). The sieve analysis of materials showed that. The size of iron powder was less than $228 \mu \mathrm{m}^{2}$, about $90 \%$ of them its size was less $115 \mu \mathrm{m}^{2}$ as clear in Figure1. The size of mill scale powder was less than $224.3 \mu \mathrm{m}^{2}$, more than $90 \%$ of them, its size was less $113.8 \mu \mathrm{m}^{2}$ as shown in Figure2. The size of starch powder was less than 33.69 $\mu \mathrm{m}^{2}$, about $90 \%$ of them, its size was less $21.18 \mu \mathrm{m}^{2}$ as given in Figure 3 . The size of glass powder was less than $670 \mu \mathrm{m}^{2}$, more than $90 \%$ of them, its size was less $300.9 \mu \mathrm{m}^{2}$ as given in Figure 4 .

Table 1: Chemical composition of iron powder, wt.\%

\begin{tabular}{|c|c|c|c|c|c|}
\hline C \% & Mn \% & Si \% & S \% & P \% & Fe \% \\
\hline 0.88 & 0.86 & 0.35 & 0.015 & 0.020 & Bal. \\
\hline
\end{tabular}

Table 2: Chemical composition of mill scale, wt.\%

\begin{tabular}{|c|c|c|c|c|c|c|c|c|c|c|}
\hline $\mathrm{SiO}_{2}$ & $\mathrm{Al}_{2} \mathrm{O}_{3}$ & $\mathrm{Fe}_{2} \mathrm{O}_{3}$ & $\mathrm{MnO}$ & $\mathrm{MgO}$ & $\mathrm{CaO}$ & $\mathrm{P}_{2} \mathrm{O}_{5}$ & $\mathrm{~S}$ & $\mathrm{Cr}_{2} \mathrm{O}_{3}$ & $\mathrm{CuO}$ & $\mathrm{LOI}$ \\
\hline 0.99 & 0.22 & 103 & 0.8 & $\begin{array}{c}0.065 \\
4\end{array}$ & 0.066 & 0.031 & 0.25 & 0.026 & 0.13 & -6.3 \\
\hline
\end{tabular}

The reason of introducing $10 \%$ mill scale to benefit from the huge amount resulted during continuous casting process of steel. The presence of $\mathrm{Fe} 2 \mathrm{O} 3$ in mill scale play an important role in slip casting process, where iron oxides react with orthophosphoric acid and water vapor realized according to Equation (1):

$$
2 \mathrm{H}_{3} \mathrm{PO}_{4}+\mathrm{Fe}_{2} \mathrm{O}_{3} \rightarrow 2 \mathrm{FePO}_{4}+3 \mathrm{H}_{2} \mathrm{O}
$$

The mechanism of the slip casting process are the steel powder $(90 \mathrm{gm})$ and mill scale $(10 \mathrm{gm})$ mixed with starch or glass powder (dispersant). The addition of $25 \mathrm{ml}$ water as a solvent with $6 \mathrm{ml}$ concentrated ortho-phosphoric acid as a source of gas (foaming agent). Liberation of water vapor as Equation (1) and as a result of liberation of $\mathrm{PO}_{3}$ gas, the steel powder is suspended. The produced sample is called green sample. The green samples were sintered - in presence of carburizing atmosphere as a result of addition of $0.5 \mathrm{gm}$ carbon powder - at $1000^{\circ} \mathrm{C}, 1100^{\circ} \mathrm{C}$ and $1200^{\circ} \mathrm{C}$. 
The density of produced steel foam after sintering at three different temperatures at different additions 3\%, 6\%, 9\% \& 12\% glass powder and starch are shown in Figs. (5-6), respectively. The apparent density of sintered foam steel decreases with increasing glass additions from $3 \%$ to $6 \%$. The behavior of apparent density was the same for sintered samples at $1000^{\circ} \mathrm{C}$ and $1100^{\circ} \mathrm{C}$ and it increasing after sintering at $1200{ }^{\circ} \mathrm{C}$ as given in Fig. 5. The apparent density of sintered sample has negative general trend with increasing addition of starch from $3 \%$ to $12 \%$ as shown in Fig. 6 .

The maximum compression load for produced steel foam after sintering at $1000{ }^{\circ} \mathrm{C}$, $1100{ }^{\circ} \mathrm{C}$ and $1200{ }^{\circ} \mathrm{C}$ after additions 3\%, 6\%, 9\% \& 12\% glass powder or starch are shown in Figs. (7-8), respectively.

It is clear that the addition of glass powder to the foam steel has negative significant effect on the compression properties as illustrated in Fig. 7. The sintering temperature has positive significant effect on compression properties in both cases addition of glass or starch. While the addition of starch has positive significant effect on compression properties as shown in Fig. 8.

The compression properties of foam steel of glass powder and starch powder can be predicted as a function in glass powder \& starch powder additions, mill scale addition and sintering temperature as given in Equations (2-3) respectively [21].

Compression test $(\mathrm{MPa})=\left(6957{ }^{*} \mathrm{~A}\right) / 2500-(36329 * \mathrm{~B}) / 15000-$

$\left(205088^{*} \mathrm{C}\right) / 375+\left(907^{\star} \mathrm{D}\right) / 37500+\left(5503^{*} A^{*} B\right) / 56250+\left(237442^{*} A^{\star} \mathrm{C}\right) / 5625$

$+\left(11656^{\star} B^{\star} \mathrm{C}\right) / 625-\left(287^{\star} A^{\star} D\right) / 225000+\left(549^{\star} B^{\star} D\right) / 125000+$

$\left(3507^{\star} C^{\star} D\right) / 6250-\left(4849^{*} A^{*} B^{\star} C\right) / 3125-\left(197^{\star} A^{*} B^{\star} D\right) / 750000-$

$\left(737^{\star} A^{*} C^{\star} D\right) / 18750-\left(1321{ }^{*} B^{*} C^{\star} D\right) / 75000+\left(691^{*} A^{*} B^{*} C^{*} D\right) / 562500-$

$132252777026106149 / 8796093022208000$

where, $\mathrm{A}=$ Glass powder in $\%, \mathrm{~B}=$ Mill Scale $\%, \mathrm{C}=$ Carbon in $\%$ and $\mathrm{D}=$ sintering Temperature $\left({ }^{\circ} \mathrm{C}\right)$

Compression test $\left(\mathrm{MPa} / \mathrm{mm}^{2}\right)=\left(6033{ }^{*} \mathrm{C}\right) / 500-\left(52867^{\star} \mathrm{B}\right) / 60000$ -

$\left(51331^{\star} A\right) / 45000+\left(557^{\star} D\right) / 20000-\left(8849^{*} A^{\star} B\right) / 450000+\left(8167^{\star} A^{\star} C\right) / 3750+$

$\left(106439^{*} B^{\star} C\right) / 15000+\left(959^{*} A^{*} D\right) / 750000+\left(853^{*} B^{*} D\right) / 1000000+$

$\left(491{ }^{*} C^{*} D\right) / 18750-\left(92621^{*} A^{*} B^{*} C\right) / 112500+\left(781^{*} A^{*} B^{*} D\right) / 7500000-$

$\left(3017^{\star} A^{\star} C^{\star} D\right) / 562500-\left(5233^{\star} B^{\star} C^{\star} D\right) / 750000+\left(1033^{\star} A^{*} B^{\star} C^{\star} D\right) / 1406250+$

$7369 / 6000$

where, $\mathrm{A}=$ Starch powder in $\%, \mathrm{~B}=$ Mill Scale $\%, C=$ Carbon in $\%$ and $\mathrm{D}=$ sintering Temperature $\left({ }^{\circ} \mathrm{C}\right)$.

Figures 9 and 10 compare between the predicted and actual compression test for steel foam with additions glass powder and starch powder respectively. As it is clear 
that the predicted compression properties of foam steel - derived from Equations 2 and 3 for glass and starch additions respectively - are in agreement with the experimental results.

\section{CONCLUSIONS}

It can be concluded that, the addition of glass or starch powder up to $6 \%$ to mixture of iron powder and mill scale powder has small negative effect on apparent density. But, increasing the percentage of glass or starch powder more than $6 \%$ has a little effect to a certain negative or positive effect on apparent density. The addition of glass powder from $3 \%$ to $12 \%$ has negative significant effect on compression properties. While, the addition of starch from $3 \%$ to $12 \%$ has positive significant effect on compression properties. The compression properties can be improved by increasing sintering temperature. The measured compression results was in a good agreement with the predicted results.

\section{ACKNOWLEDGMENT}

The authors thank Central Metallurgical Research \& Development institute (CMRDI), Egypt for supplying the raw materials, melting shop, and characterization tools.

\section{REFERENCES}

[1] J. Banhart, " Manufacture, characterization and application of cellular metals and metal foams" Prog. Mater. Sci.,Vol. 46, No. 1, pp. 559-632 (2001).

[2] P. Åsholt, "Metal Foams and Porous Metal Structures", ed. J. Banhart, M.F. Ashby, and N.A Fleck (Bremen, Germany: MIT-Verlag), p. 133 (1999).

[3] J. Wood, "Metal Foams",ed. J. Banhart and H. Eifert (Bremen, Germany: MITVerlag), p. 31 (1997).

[4] O. Prakash, H. Sang, and J.D. Embury, "Structure and properties of Al-SiC Foam”, Mater. Sci. Eng., Vol. A199, No. 2, pp. 195-203, (1995).

[5] L.D. Kenny," Manufacturing of Aluminum Foams from PMMC Melts Material Characteristics and Typical Properties in Metal" Mater. Sci. Forum, Vol. 217222, p.1883 (1996).

[6] A.E. Simone and L.J. Gibson, "Aluminium foams produced by liquid state processes.", Acta Mater., Vol. 46, pp. 3109-3123 (1998).

[7] J.T. Beals and M.S. Thompson, "Density Gradient Effects on Aluminium Foam Compression Behaviour”, J. Mater. Sci., Vol. 32, pp. 3595-3600, (1997).

[8] T. Miyoshi, in Ref. 2, p. 125, https://books.google.com.eg/books?isbn=0080872182

[9] L. Ma, Z. Song, "Cellular structure control of aluminium foams during foaming process of aluminium melt", Scripta Mater., Vol. 39, No. 11, pp. 1523-1528 (1998).

[10] V. Shapovalov, "Porous and Cellular Materials for Structural Applications", Vol. 521, p. 28,1ed. D.S. Schwartz et al. (Warrendale, PA: MRS) (1998).

[11] F. Baumgärtner, I. Duarte, and J. Banhart, "Industrialisation of P/M foaming process”, Adv. Eng. Mater., Vo.2, pp.168-174 (2000). 
[12] I. Duarte and J. Banhart, "A study of aluminium foam formation - kinetics and microstructure", Acta Mater., Vol. 48, pp.2349-2362 (2000).

[13] J. Banhart and J. Baumeister, "Deformation Characteristics of Metal Foams", J. Mater. Sci., Vol. 33, pp. 1431-1440 (1998).

[14] T. Höpler, F. Schörghuber, and F. Simancík, "Manufacturing Routes for Metallic Foams - TMS“, in Ref. 2, p. 79 (1999).

[15] J. Baumeister, "Sandwich Construction " Vol. I, ed. H.R. Meyer-Piening and D. Zenkert (Solihull, U.K.: EMAS Publishing, 2000), p. 339 (2000).

[16] J. Banhart et al., "Aluminium" Vol. 76, P. 491 (2000).

[17] W. Seeliger, "Handbook of cellular metals: production, processing, applications", in Ref. 2, p. 29 (2002).

[18] J. Banhart et al., German patent 19,813,176 (1998).

[19] V. Gergely and T.W. Clyne, "The FORMGRIP process: foaming of reinforced metals by gas release in precursors", Adv. Eng. Mater., Vol. 2, No. 4, p. 175, 2 (2000), p. 175.

[20] A. Fathy, A. Ahmed, H. Morgan; " Characterization and optimization of steel foam produced by slip casting process", MetFoam 2007 Conference Porous Metals and Metallic Foams - Sept. 5 - 7, 2007, pp 161-164, Montreal, Canada.

[21] S. Ghali, H. El-Faramawy \& M. Mishreky "Factors affecting the compression properties of steel foam ", $2^{\text {nd }}$ Intr. Conf. on Michanics of Composites, 11-14 July 2016, Universidade do Porto, Portugal. 

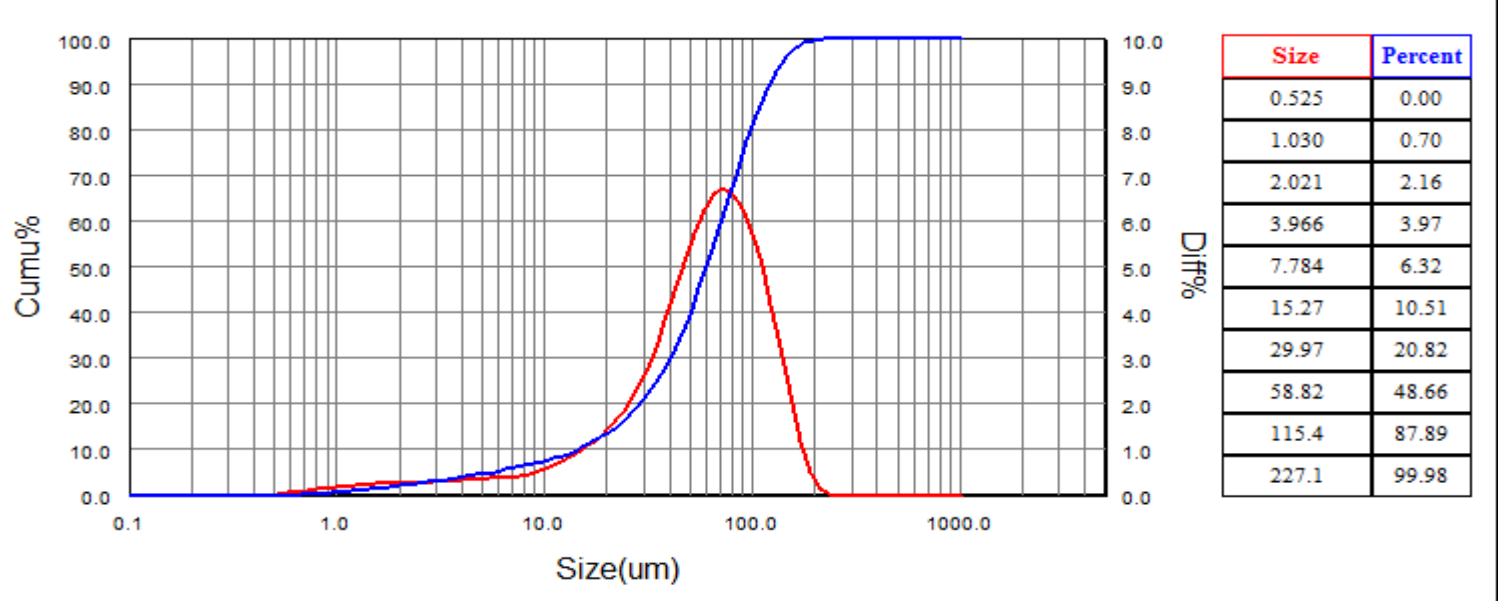

Fig. 1. Sieve analysis of iron powder (red line represents the size and blue line represents the cumulative percentages).
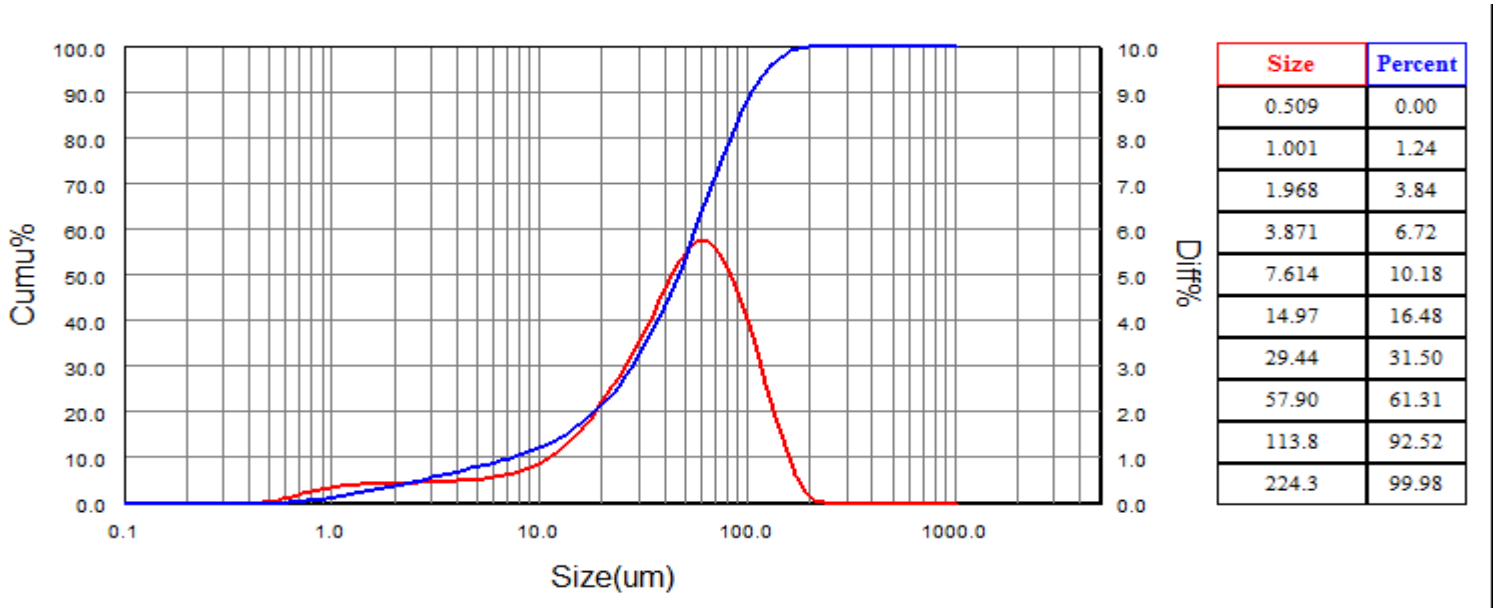

Fig. 2. Sieve analysis of mill scale (red line represents the size and blue line represents the cumulative percentages).
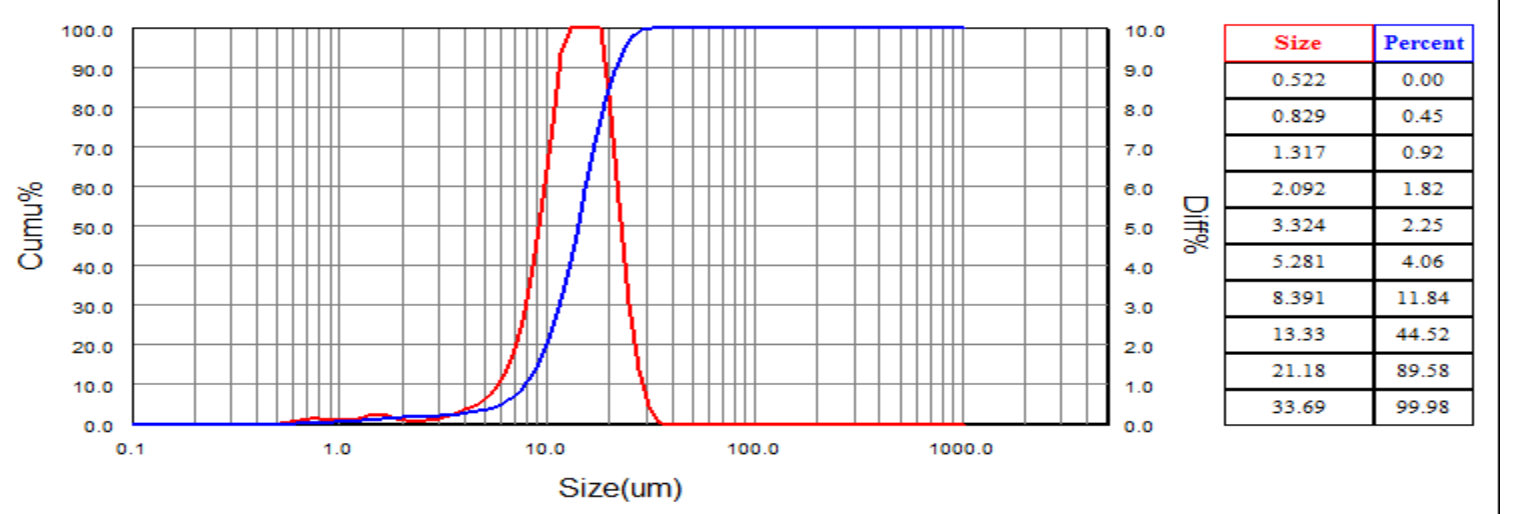

Fig. 3. Sieve analysis of starch(red line represents the size and blue line represents the cumulative percentages). 

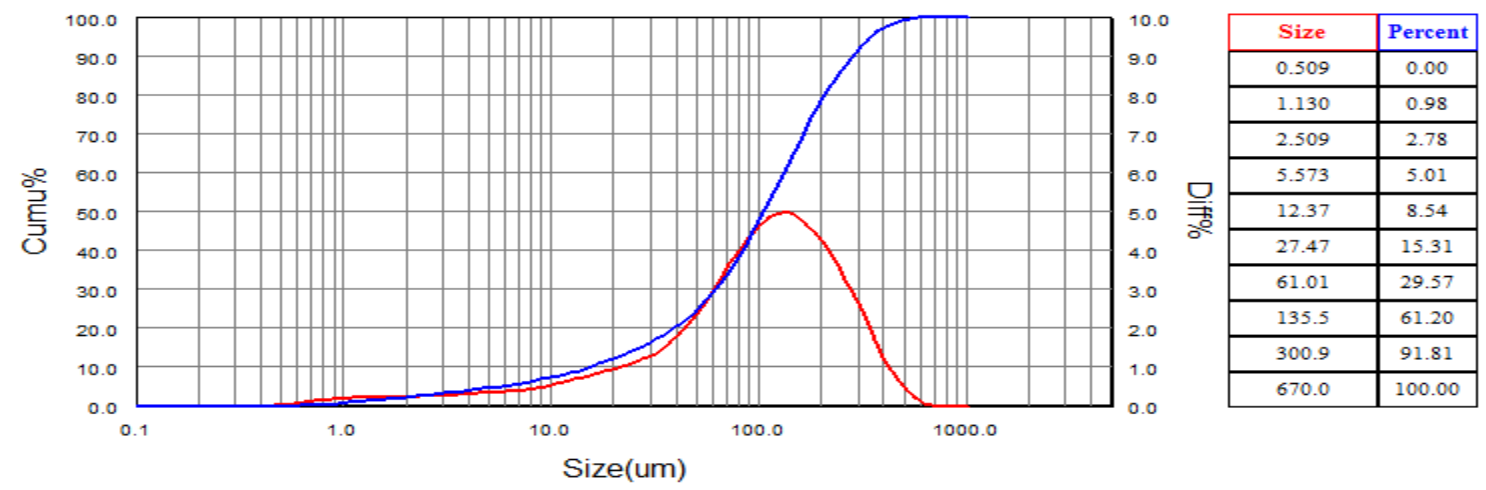

Fig. 4. Sieve analysis of glass powder (red line represents the size and blue line represents the cumulative percentages).

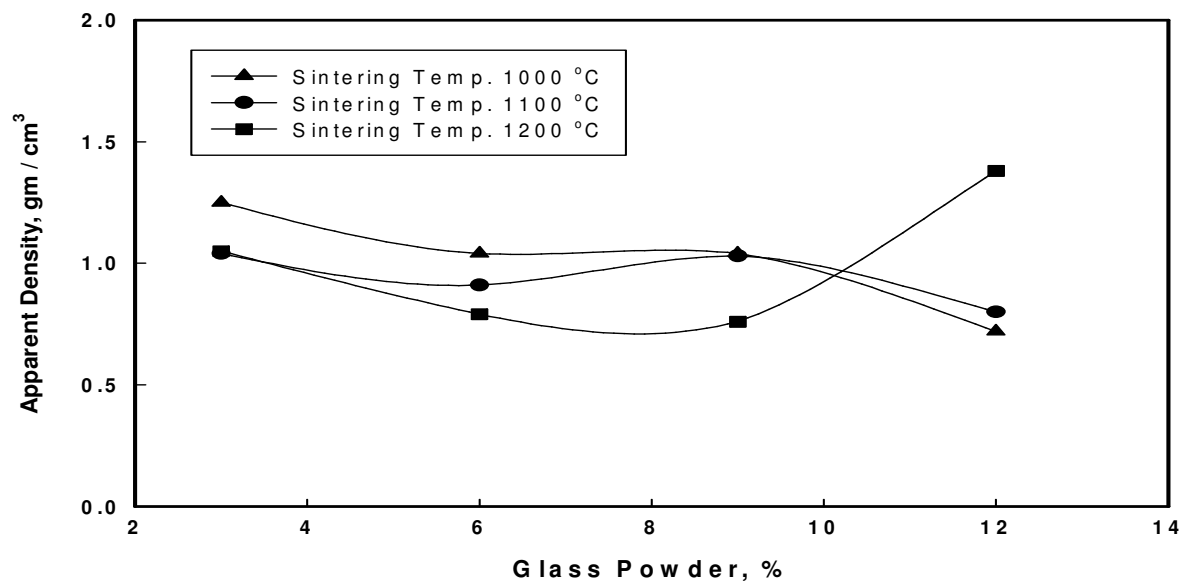

Fig. 5. The influence of glass powder addition on apparent density of mixture $(10 \%$ mill scale $+90 \%$ steel powder) at different sintering temperatures

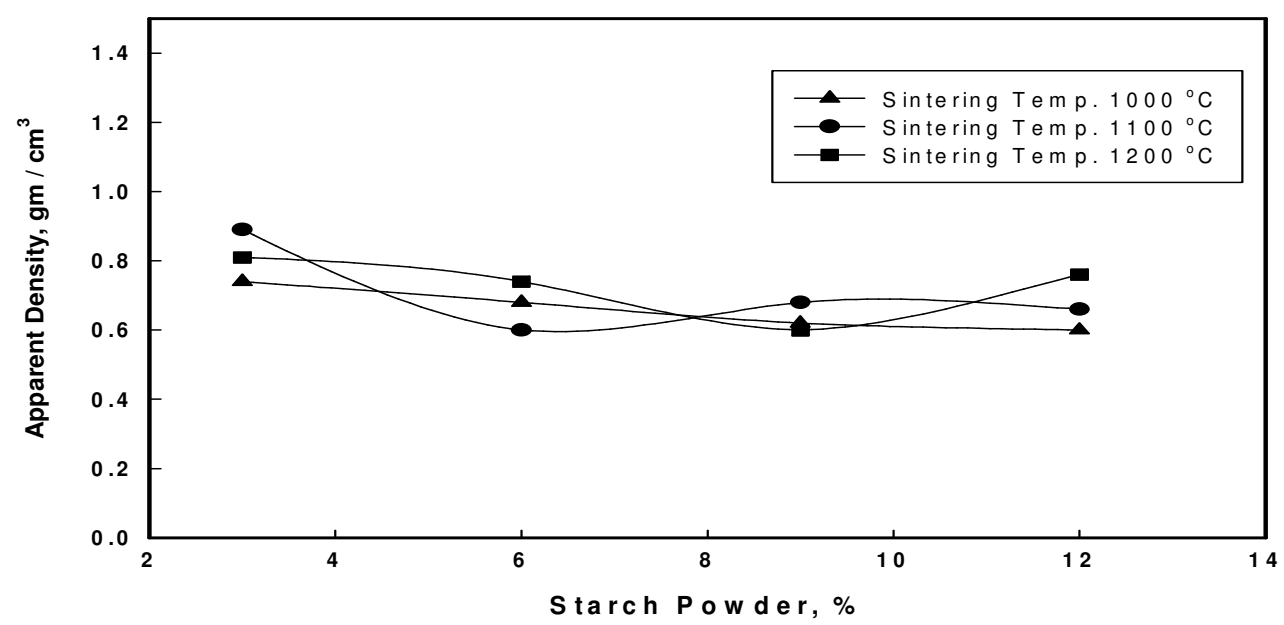

Fig. 6. The influence of starch powder addition on apparent density of mixture $(10 \%$ mill scale $+90 \%$ steel powder) at different sintering temperatures 


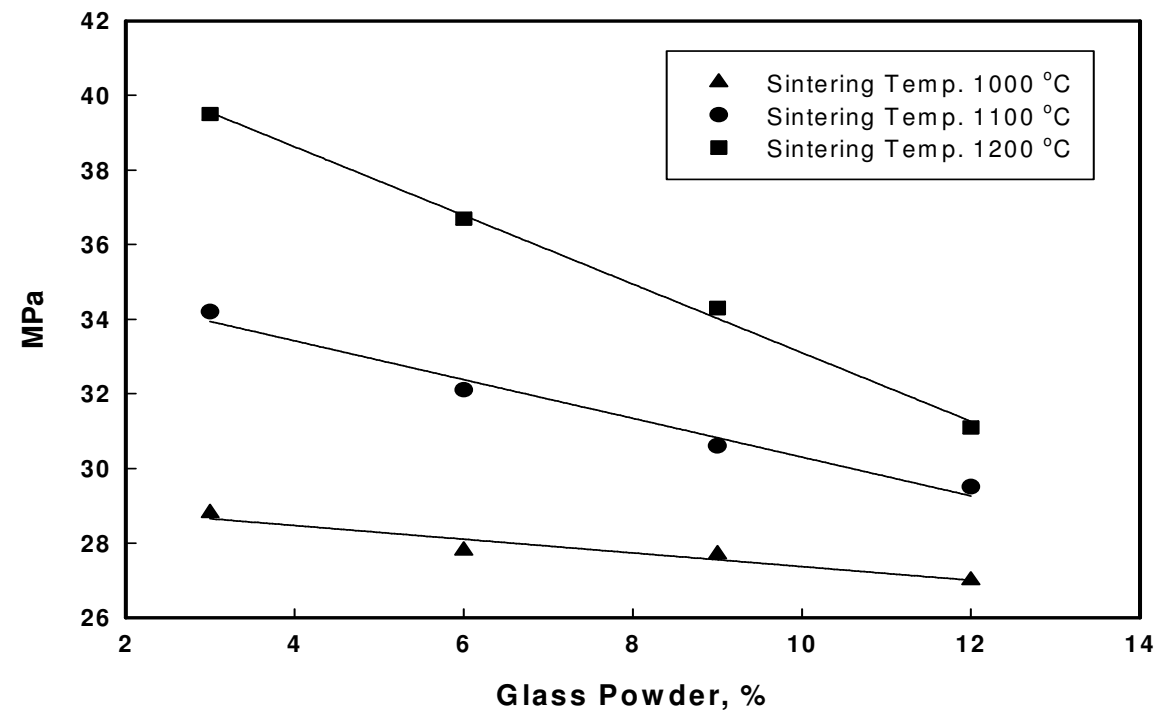

Fig. 7. The influence of glass powder addition on compression properties of mixture $(10 \%$ mill scale $+90 \%$ steel powder) at different sintering temperatures

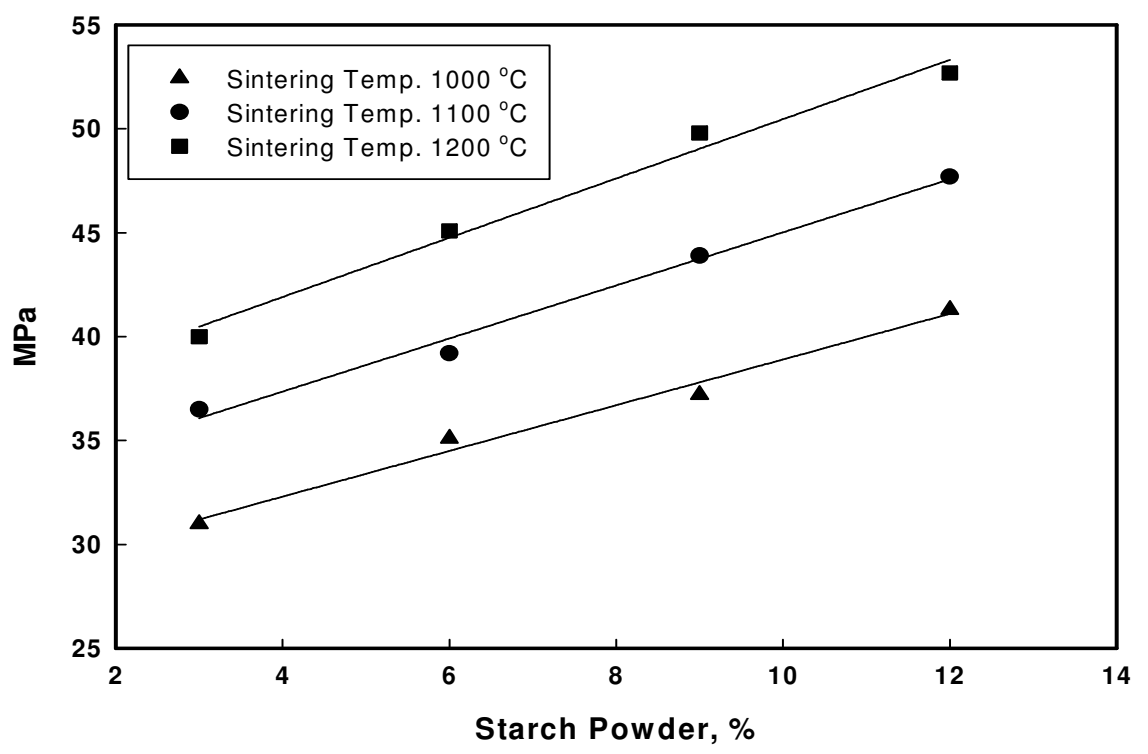

Fig. 8: The influence of starch powder addition on compression properties of mixture $(10 \%$ mill scale $+90 \%$ steel powder) at different sintering temperatures. 


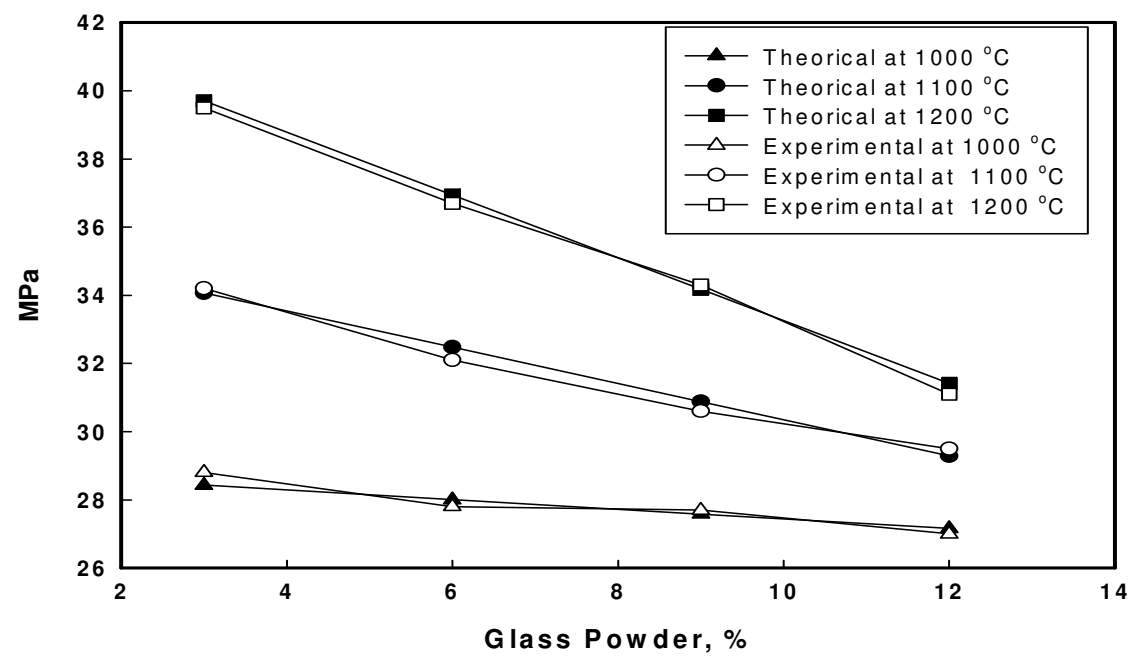

Fig. 9. Comparison between experimental and predicted compression properties of mixture $(10 \%$ mill scale $+90 \%$ steel powder $)$ with different glass powder additions at different sintering temperatures

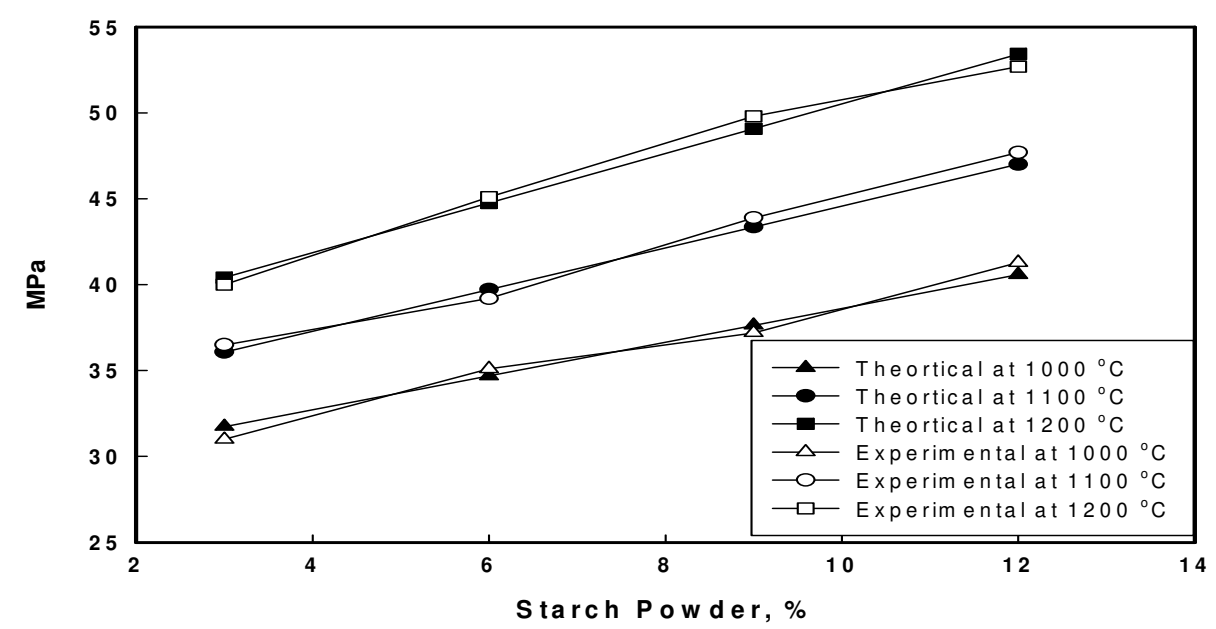

Fig. 10: Comparison between experimental and predicted compression properties of mixture (10\% mill scale $+90 \%$ steel powder) with different starch powder additions at different sintering temperatures 